\title{
XXXI. On the factors serving to determine the direction of sound
}

\section{T.J. Bowlker}

To cite this article: T.J. Bowlker (1908) XXXI. On the factors serving to determine the direction of sound, Philosophical Magazine Series 6, 15:87, 318-332, DOI: 10.1080/14786440809463775

To link to this article: http://dx.doi.org/10.1080/14786440809463775

Published online: 16 Apr 2009.

Submit your article to this journal $\longleftarrow$

Џll Article views: 5

Q View related articles $\longleftarrow$

Citing articles: 5 View citing articles 5 
between $\mathrm{my}$ theory and experimental facts in the electrodynamics of the relative uniform motion of electric and magnetic masses, the Lorentz theory finds unsurmountable difficulties on theoretical grounds. As was first conclusively shown by Abraham, the Lorentz deformation excludes a purely electromagnetic basis of mechanics. The work of the external electric forces acting on the electron does not have its exact equivalent in the increase of the electromagnetic energy of the electron. Therefore a certain inner energy of non-electromagnetic character must be ascribed to the electron. The same conclusion must be drawn from Mr. Cunningham's calculations, if they are properly interpreted.

Mr. Cunningham says the Lorentz-Einstein theory is the only theory that can account for certain optical phenomena. In fact, he asserts that it is required "to explain how a light-wave travelling outwards in all directions with velocity Crelative to an observer A may at the same time be travelling outwards in all directions with the same velocity relative to an observer B moving relative to A with velocity $v$." Mr. Cunningham then proceeds to show that this requirement is satisfied by the Lorentz-Einstein transformation.

I am not aware that such a " requirement" is necessary to explain any known fact of observation.

XXXI. On the Factors serving to determine the Direction of Sound. By T. J. BowlkER* *

$\mathbf{I}^{\mathrm{N}}$ $\mathrm{N}$ the summer of 1906 , while on a steamship off the coast. of Maine, U.S.A., I was roused about midnight by the blowing of foghorns, and presently followed the shock and grinding of a collision. It appeared to me that the accident could only be explained by a mistake in judging of the direction of the foghorns of the colliding vessels. This accident suggested a study of the factors determining the direction from which sound appears to come.

During the winter of 1906-1907 I made some experiments. In one of them I placed the ends of two rubber tubes of equal lengths at the ears and moved the end of one towards or away from the source of sound. With equal lengths of tube I thought that the friction and resonance effects would be the same. The sound, as heard through the tubes, did appear to move somewhat to one side or other of the head, but the movements did not appear to have any relation to the wave-length, and the movements were very irregular.

* Communicated by the Author. 
I realized how hopeless it was to try such experiments in a small laboratory where periaps 90 per cent. or more of the sound had already suffered one or more reflexions; the experiment merely suggested a possible method of studying the position of nodes and antinodes in such a closed space.

Later an apparatus to determine the direction of sound by magnifying the intensity effects by means of two soundreceivers on opposite sides of a large flat board was surprisingly inadequate except in the case of the higher notes, and led to the conclusion that it was very probable that phase had a good deal to do with our judgment of the direction of sound.

I postponed further experiments on the direction of sound until the summer of 1907 , when I should have an opportunity of trying them in the open air.

In the meantime I saw Lord Rayleigh's paper in the Philosophical Magazine proving conclusively, in an ingenious manner in the laboratory, that phase in some cases gave a sense of direction. It only remained to show to what extent and within what limits these effects were produced. In June 1907 therefore I proceeded to try experiments in the open air, the apparatus being a set of adjustable organpipes, made for me by Hutchings \& Votey of Cambridge, Mass., and cylindrical tubes of various lengths applied to the ears.

The tubes were of sheet aluminium, and they could have their length altered by sliding one within another. $2 \frac{1}{4}$ inches was chosen as the diameter, because then the tube could be readily fitted quite closely round its whole circumference against the head.

The source of sound was placed at a distance of about 30 feet from the observer in an open field. It was at once found that with two unequal tubes applied to the ears, and with the observer facing the source of sound, the source appeared to move to the opposite side to that on which the longer tube was applied. (This, as will be seen later, is only true within certain limits.)

After certain preliminary experiments, the ground was pegged out in an arc of a circle $28 \frac{1}{2}$ feet in radius. The source of sound was placed at a point of this arc, and pegs were placed at intervals of $4^{\circ}$ along the circumference up to $60^{\circ}$ on each side of the source. The observer was situated at the centre of the circle. As the image of the source moved the observer continually faced the image and noted its apparent position on the arc. This position could be fixed with an error of not more than one or two degrees. 
Some of the results obtained are given in the table below. In order to avoid psychological errors of imagination and expectation, no guesses at what would happen were made, nor any theory formed as to the probable position of the imas, until two or three complete sets of experiments had been made. It was found, however, that after a little practice the location of the image could usually be obtained with such certainty that these precautions were unnecessary.

In the following tables $r$. indicates that the tube was over the right ear or that the movement of the sound-image was to the right, whilst $l$. indicates the same for the left.

$L$ is the length from the extremity of one tube to the extremity of the other when both are applied to the head.

$\theta$ is the angular displacement of the image when the longer tulve is nearer the source.

$\theta^{\prime}$ is the angular displacement when the shorter tube is nearer the source.

Note of Wave-length $=19$ inches.

\begin{tabular}{|c|c|c|c|c|}
\hline $\begin{array}{l}\text { Length of } \\
\text { tubes over } \\
\text { ears. }\end{array}$ & $\begin{array}{c}\text { Diff. of } \\
\text { length of } \\
\text { ear-tubes }=\mathrm{D}\end{array}$ & $\left\{\begin{array}{c}\text { Displacement } \\
\text { of } \\
\text { image }=\theta .\end{array}\right.$ & $\begin{array}{c}\mathrm{L} \sin \theta . \\
\theta=\text { angle to } \\
\text { the left. }\end{array}$ & $\begin{array}{l}L \sin \theta^{\prime}+\mathrm{J} . \\
\theta^{\prime}=\text { angle to } \\
\text { the right. }\end{array}$ \\
\hline Inches. & Inches. & & Inches. & Inches. \\
\hline $\left.\begin{array}{l}7 \text { over r. } \\
6 \text { over }\end{array}\right\}$ & 1 & $2^{\circ} 1$. & 6 & \\
\hline $\left.\begin{array}{l}8 \mathrm{rr} . \\
6 \mathrm{l} .\end{array}\right\} \ldots$. & 2 & $6^{\circ} 1$ & $2 \cdot 1$ & \\
\hline $\left.\begin{array}{l}9 \mathrm{r} . \\
6 \mathrm{l} .\end{array}\right\} \ldots$ & 3 & $8^{\circ} 1$ & $2 \cdot 9$ & \\
\hline $\left.\begin{array}{rl}10 & \mathrm{r} . \\
6 \mathrm{l} .\end{array}\right\} \ldots .$. & 4 & $10^{\circ} 1$. & $3 \cdot 7$ & \\
\hline $\begin{array}{r}12 \mathrm{r} . \\
6 \mathrm{l} .\end{array}$ & 6 & $16^{\circ} 1$ & $6 \cdot 7$ & \\
\hline $\begin{aligned} 14 \mathrm{r} . \\
6 \mathrm{l} .\end{aligned}$ & 8 & $10^{\circ} 1$. & $4 \cdot 4$ & \\
\hline $\begin{array}{c}15 \frac{1}{2} \mathrm{r} . \\
61 .\end{array}$ & $9 \frac{1}{2}$ & $\left\{\begin{array}{l}20^{\circ} 1 . \text { and } \\
20^{\circ} \text { r. \& } 0^{\circ}\end{array}\right.$ & $9 \cdot 2$ & $18 \cdot 7$ \\
\hline $\begin{array}{rl}18 & \text { r. } \\
6 & 1 .\end{array}$ & 12 & $\left\{\begin{array}{r}24^{\circ \prime} 1 \\
8^{\circ} \mathrm{r}\end{array}\right.$ & $12 \cdot 3$ & $16 \cdot 2$ \\
\hline $\left.\begin{array}{r}19 \mathrm{r} . \\
6 \mathrm{l},\end{array}\right\} \ldots$ & 13 & $\left\{\begin{array}{c}26^{\circ} \mathrm{l} \\
6^{\circ} \mathrm{r}\end{array}\right.$ & $13 \cdot 6$ & $16 \cdot 1$ \\
\hline
\end{tabular}

Now if an image, apparently in front, is produced when the phases arriving at the ear are in agreement, $L \sin \theta$ should be equal to the difference of length of the ear-tubes, and $\mathrm{L} \sin \theta^{\prime}+\mathrm{D}$ should be approximately equal to the wavelength. We find that this is the case. There are, however, some anomalies, notably when the angle suddenly changes from $16^{\circ}$ l. with a tube 12 inches long over the right ear to 
$10^{\circ}$ l. when the tube is made 14 inches long. This is doubtless due to resonance in the 14-inch tube increasing the intensity at the right ear. Subsequent experiments confirmed this view. In later experiments large loose wads of cottonwool were inserted at the outer ends of the tubes. This proves a very effective means of checking resonance, whilst not interfering very much with the intensity. In this manner, using sounds of various wave-lengths, it was proved that an image appeared in front of the observer when the phases of the waves arriving at the ears were approximately in agreement. A better arrangement was devised, however, later, and an account of these later experiments appears further on.

The next point was to determine, to what extent the image of the source was displaced whilst the observer continually faced the source, and how this displacement depended on the wave-length. For this purpose two tubes were taken, and the observer continually faced the source and tried to note the direction in which the image appeared: in some cases only one tubie was applied to the ear.

One example is given below.

Note of Wave-length 26.8 inches.

\begin{tabular}{|c|c|c|c|c|c|}
\hline $\begin{array}{c}\text { Length of } \\
\text { tube placed } \\
\text { over one } \\
\text { ear-the } \\
\text { other ear } \\
\text { free. }\end{array}$ & $\begin{array}{l}\text { Angular dis- } \\
\text { placement of } \\
\text { sound-image } \\
\text { with tube over } \\
\text { the right ear. }\end{array}$ & $\begin{array}{c}\text { Angular dis- } \\
\text { placement of } \\
\text { sound-image } \\
\text { with tube over } \\
\text { the left ear. }\end{array}$ & $\begin{array}{c}\text { Lengths of } \\
\text { tubes placed } \\
\text { over the } \\
\text { two ears. }\end{array}$ & $\begin{array}{l}\text { Angular dis- } \\
\text { placement } \\
\text { with the } \\
\text { longer tube } \\
\text { over the } \\
\text { right ear. }\end{array}$ & $\begin{array}{l}\text { Angular } \\
\text { displace- } \\
\text { ment with } \\
\text { the longer } \\
\text { tube over } \\
\text { the left ear }\end{array}$ \\
\hline 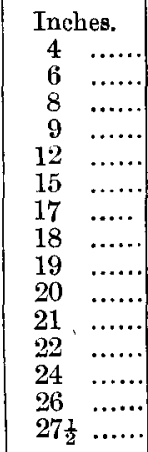 & $\begin{array}{c}4^{\circ} \mathrm{l} . \\
8^{\circ} \mathrm{l} . \\
20^{\circ} \mathrm{l} . \\
24^{\circ} \mathrm{l} . \\
36^{\circ} \mathrm{l} . \\
40^{\circ} 1 . \& 46^{\circ} \mathrm{r} \\
40^{\circ} \mathrm{r} . \\
30^{\circ} \mathrm{r} . \\
20^{\circ} \mathrm{r} . \\
10^{\circ} \mathrm{r} . \\
0^{\circ} \\
0^{\circ} \\
4^{\circ} 1 . \\
10^{\circ} \mathrm{i} . \\
20^{\circ} \mathrm{l} .\end{array}$ & $\begin{array}{c}2^{\circ} \mathbf{r .} \\
4^{\circ} \mathbf{r} . \\
10^{\circ} \mathbf{r .} \\
16^{\circ} \mathbf{r .} \\
24^{\circ} \mathbf{r} \\
30^{\circ} \mathbf{r} \& 30^{\circ} 1 . \\
40^{\circ} \text { r. } \& 40^{\circ} 1 . \\
30^{\circ} 1 . \\
24^{\circ} \mathrm{l} . \\
16^{\circ} \mathrm{l} . \\
8^{\circ} \mathrm{l} . \\
0 \\
0 \\
4^{\circ} \mathbf{r} . \\
8^{\circ} \mathbf{r} .\end{array}$ & \begin{tabular}{rr}
\multicolumn{2}{c}{ Inches. } \\
9 & $\& 6$ \\
12 & $\& 6$ \\
& \\
15 & $\& 6$ \\
17 & $\& 6$ \\
19 & $\& 6$ \\
$23 \&$ & $\& 6$ \\
25 & $\& 6$ \\
& \\
28 & $\& 6$ \\
28 & $\& 4$
\end{tabular} & $\begin{array}{c}16^{\circ} 1 . \\
28^{\circ} \mathrm{l} . \\
40^{\circ} \mathrm{l} \\
60^{\circ} 1 . \& 60^{\circ} \mathrm{r} \\
30^{\circ} \mathrm{r} . \\
12^{\circ} \mathrm{r} . \\
4^{\circ} \mathrm{r} .\end{array}$ & $\begin{array}{l}4^{\circ} \mathrm{r} . \\
8^{\circ} \mathrm{r} . \\
14^{\circ} \mathrm{r} . \\
20^{\circ} \mathrm{r} . \\
45^{\circ} \mathrm{r} . \\
30^{\circ} \mathrm{r} . \\
(?) 0^{\circ} \mathrm{r} . \& \\
(?) 0^{\circ} \mathrm{l} . \\
\\
\text { (?) } 0^{\circ} \mathrm{l} . \\
0\end{array}$ \\
\hline
\end{tabular}

It would appear from the above that the image crosses over from left to right, or from right to left, when there is a 
difference of about half a wave-length in the arrival of the sound at the two ears-the image being on that side at which the sound-wave arrives first.

It will be noted that in the earlier stages a displacement was more readily produced when the phase was advauced on the left ear. I was thus asymmetric with regard to my hearing, and I have found the same to be true of others.

I also found that the hearing mechanism connected with the formation of the position of the image is capable of fatigue. After listening intently for some time with one ear towards the source, the position of the image does not return to exactly the same place as before. I. tried to determine whether fatigue for one note resulted in a lessened displacement of the sound-image of another note, but $I$ was unable to settle this point. These phenomena may be of interest to the experimental psychologist.

Similar experiments were tried with notes of other wavelengths, the result always indicating that there was a sudden appearance of an image on the other side of the field of sound-view when the difference of phase at the two ears was approximately half a wave-length. The maximum angle of displacement increased up to $90^{\circ}$ as the wave-length of the sound increased ; a wave-length of about 36 inches being the first that gave an image displaced $90^{\circ}$. Sounds with longer wavelength gave a displacement of $90^{\circ}$ before a phase-difference of half a wave-length was reached, and the sound-image then seemed to spread over a continually incrensing length of arc on each side of $90^{\circ}$.

It is hard to determine the actual position of a soundimage when the observer is facing the source, and the soundimage is displaced through a large angle. Up to $20^{\circ} \mathrm{I}$ think I can tell the position to within $2^{\circ}$, from $20^{\circ}$ to $30^{\circ}$ to within $4^{\circ}$, from $30^{\circ}$ to $40^{\circ}$ to within $6^{\circ}$, from $40^{\circ}$ to $50^{\circ}$ to within $8^{\circ}$, after $55^{\circ}$ I may be $10^{\circ}$ or more out. When possible I find it best to point with the arm outstretched in the direction from which the sound appears to come, but when holding two tubes to the ears one cannot do this.

In the above experiments resonance effects were still rather disturbing, and, as the general behaviour of the soundimages had been ascertained, a new arrangement was introduced.

In this the ear-tubes were of equal length, and a rightangled bend was inserted in each, so that the outer portions of the tubes were approximately vertical. The plane through the outer edges of these tubes was horizontal. 
With this arrangement the resonance was the same in both tubes, and the intensity was also the same for both.

The distance apart of the centres of the tubes was 31 inches, and their diameter was 2 inches. The tubes were luted into the right-angled berd with stiff modelling-clay.

With this arrangement, when facing the source, the image did not always coincide exactly with the source, perhaps owing to the tubes being slightly unsymmetrical with regard to the head when closeiy pressed against it to make a tight joint at the junction of head and tube.

The method of procedure was-first to find the true zero by applying the ear-tubes and facing the source, then turning the head until the image appeared to be straight in front and then noting the realing. (The error here would probably not be more than $1^{\circ}$.) Then the head was turned slowly to the left, this caused the image to move more or less to the right, at a certain position in the rotation of the head an image appeared suddenly to the left-this new image made an angle with the symmetric vertical head plane approximately equal to the angle the original image now made with it. This point is called the "two-image" point, and the angle that the image makes with the vertical head plane at this point is called the "cross-over" angle. It is near the maximum displacement that phase will produce with the particular wave-length under observation.

After this "two-image" point has been noted, the head is still turned towards the lett until the new image appears directly in front. This point can usually be found within $1^{\circ}$ or $2^{\circ}$. The procedure is repeated to the right.

The results obtained are as follows :-

With Note of Wave-length 51 inches.

Zero at $4^{\circ}$ left.

"Two-image" point at $57^{\circ}$ left, no such point to the right.

"Cross-over angle" from $90^{\circ}$ right (wide image) to $90^{\circ}$ left (wide image). These images were over several degrees of are to right and left of $90^{\circ}$.

The "two-image" point $57^{\circ}$ left, if we take it as occurring at a difference of phase equal to half a wave-length, and reckon from the zero at $4^{\circ}$ left, gives us $2\left(31 \sin 53^{\circ}\right)=49 \cdot 6$ inches as the wave-length. 
"Two-image point" at $40^{\circ}$ left and $38^{\circ}$ right.

"Cross-over angle" from $90^{\circ}$ right (wide image) to $90^{\circ}$ left (wide image).

Taking $39^{\circ}$ for the mean position of the two-image point, we get $2\left(31 \sin 39^{\circ}\right)=39$ inches as the wave-length.

Note of Wave-length $27 \cdot 6$ inches.

$$
\text { Zero at } 4^{\circ} \text { left. }
$$

"Two-image point"...22 $2^{\circ}$ r. and $30^{\circ} \mathrm{l}$. (mean $26^{\circ}$ ).

New images ........... $51^{\circ}$ r. and $55^{\circ} 1$. (mean $53^{\circ}$ ).

Cross-over angle from $50^{\circ}$ right to $40^{\circ}$ left and from $40^{\circ}$ left to $40^{\circ}$ right.

Wave-length from "two-image point"

$$
=2 \times 31 \sin 26^{\circ}=27 \cdot 3 \text { inches. }
$$

Wave-length from new images

$$
=31 \sin 53^{\circ}=24.8 \text { inches. }
$$

Note of Wave-length $19 \cdot 4$ inches.

$$
\text { Zero at } 0^{\circ} \text {. }
$$

"Two-image point... $19^{\circ}$ l. and $16^{\circ}$ r. (mean $\left.171^{\circ}\right)$.

New images ........4.4 $42^{\circ} \mathrm{l}$. and $46^{\circ} \mathrm{r}$. (mean $44^{\circ}$ ).

Cross-over angle $\ldots 36^{\circ} \mathrm{r}$. to $36^{\circ} \mathrm{l}$.

$$
\text { and } 36^{\circ} \mathrm{l} \text {. to } 36^{\circ} \mathrm{r} \text {. }
$$

Wave-length from "two-image point"

Wave-length from new images

$$
=2 \times 31 \sin 17 \frac{1}{2}^{\circ}=18.6 \text { inches. }
$$

$$
=31 \sin 44^{\circ}=21.4 \text { inches. }
$$

Note of Wave-length 13.8 inches.

$$
\text { Zero at } 0^{\circ} \text {. }
$$

"Two-image point" $\ldots 17^{\circ} \mathrm{I} ., 17^{\circ} \mathrm{r}$.

New images ...........2 $29^{\circ} \mathrm{l}, 62^{\circ} \mathrm{l}$ l., $29^{\circ} \mathrm{r} ., 68^{\circ} \mathrm{r}$.

Cross-over angle ...... 18 $18^{\circ}$ to $18^{\circ}$.

Wave-length from "two-image point"

$$
=2 \times 31 \sin 17^{\circ}=18 \text { inches. }
$$

Wave-length from new images

$$
\begin{aligned}
& =31 \sin 29^{\circ}=14 \cdot 9 \text { inches. } \\
& \text { and } \frac{31 \sin 65^{\circ}}{2}=14 \cdot 1 \text { inches. }
\end{aligned}
$$


Note of Wave-length 10.4 inches.

Zero at $3^{\circ} \mathrm{r}$.

“Two-image point"... $13^{\circ} 1 ., 18^{\circ} \mathrm{r} ., 41^{\circ} 1$.

New images ........... $24^{\circ}$ l., $23^{\circ}$ r., $50^{\circ} \mathrm{l}$.

Cross-over angle ...... $15^{\circ}$ to $15^{\circ}$.

Wave-length from first pair of two-image points

$$
=2\left(31 \sin 15 \frac{1}{2}^{\circ}\right)=16.7 \text { inches. }
$$

From first pair of new images

From next image

$$
=31 \sin 23 \frac{1}{2}^{\circ}=12.4 \text { inches. }
$$

$$
=\frac{31 \sin 53^{\circ}}{2}=12 \cdot 4 \text { inches. }
$$

Below this wave-length the images were too near together to have their position clearly determined, the sound of one image confusing the apparent position of the other image.

Sometimes it appeared as if three images were in the field together, then the one nearest the source would appear the loudest and draw off the attention from, and apparently obscure the image directly in front of the observer.

The tubes were shortened so that the distance between the centres of their ends was reduced to 15 inches.

With this pair of shortened tubes the following results were obtained :-

$$
\begin{aligned}
& \text { Wave-length } 10.4 \text { inches. } \\
& \text { Zero at } 0^{\circ} \text {. }
\end{aligned}
$$

“Two-image point"... $22^{\circ}$ l.

New images at ......... $41^{\circ} 1 . \& 40^{\circ} \mathrm{r}$.

Cross-over angle ......2 20 $0^{\circ}$. to $20^{\circ} \mathrm{r}$.

Here the two images were heard with the head facing anywhere over the arc from $12^{\circ} \mathrm{r}$. to $30^{\circ} \mathrm{r}$. and from $12^{\circ} \mathrm{l}$.to $30^{\circ} \mathrm{l}$.

Wave-length by two-image point

$$
=2 \times 15 \sin 22^{\circ}=11 \cdot 1 \text { inches. }
$$

Wave-length by new images

$$
\begin{aligned}
& =15 \sin 40 \frac{1}{2}^{\circ}=9 \cdot 8 \text { inches. } \\
& \text { Wave-length } 8 \text { inches. }
\end{aligned}
$$

"Two-image point"--two images were evident during nearly the whole range-there were practically always two and sometimes three images evident, though I had some doubts whether the central image was always real or a result of attention to the two side images.

New images......2 $24^{\circ} 1 . \& 21^{\circ} \mathrm{r}$.

Cross-over angle $12^{\circ}, i$. e. the maximum angle of displacement was $12^{\circ}$.

Wave-length by new images $=15 \sin 22 \frac{1}{2}^{\circ}=5 \cdot 7$ inches. 
So far the tubes had been used with the full aperture-a circle of 2 inches diameter. Now they were closed by disks luted on with modelling-clay-the disks being perforated by holes $\frac{6}{10}$ of an inch in diameter.

Note of Wave-length 6.4 inches.

$$
\text { Zero } 4^{\circ} 1 \text {. }
$$

Images at $24^{\circ}$ l. and $22^{\circ} \mathrm{r}$.; but now three images could always apparently be heard together when facing one of them. When blowing the note hard the central image could be heard most strongly, but as the sound gradually ceased the central image died away, first leaving the impression that the two side images only existed.

Cross-over angle-or maximum angle of displacement of image about $9^{\circ}$.

Wave-length by new images $=15 \sin 23^{\circ}=5 \cdot 8$ inches.

Note of Wave-length $5 \cdot 8$ inches.

$$
\text { Zero at } 0^{\circ} \text {. }
$$

Images at $16^{\circ} \mathrm{l}$, and $14^{\circ} \mathrm{r}$.

When facing the image at $16^{\circ} \mathrm{l}$. the image further to the left seemed stronger and tended to draw off one's attention. When facing $14^{\circ} \mathrm{r}$. the image at the source, which now appears only about $8^{\circ}$ to the left, tends to obscure the image in front at $14^{\circ} \mathrm{r}$.

Maximum displacement $6^{\circ}$ or $\varepsilon^{\circ}$.

Wave-length by images $=15 \sin 15^{\circ}=3.9$ inches.

\section{Note of Wave-length 4.4 inches.}

Here it was very difficult to determine even approximately the position of an image, the one to the left of the two or three in the field of view seeming the loudest as a rule. I thought I had images in front, however, at $8^{\circ} \mathrm{r} ., 10^{\circ} \mathrm{l}$., $22^{\circ} 1$, $36^{\circ} 1$., but it was impossible to distinguish between having an image directly in front and having a two-image point in front. I only felt sure that phase was still playing a part in fixing the maxima and minima which gave rise to the centres of the sound images.

From the measurements of the maximum angle of displacement that I had taken in the above experiments it would seem that for wave-lengths below 20 inches the angle of 
displacement* was very roughly proportional to the wavelength-for a wave-length of $4 \cdot 4$ inches the displacement would only be $5^{\circ}$ or $6^{\circ}$.

Now, to produce a difference of phase of half a wave-length the head, without the tubes, would bave to be turned through about $23^{\circ}$-so if the head faced the source and was then turned to one side or the other, the image would appear to following the turning of the head if the intensity remained the same at the two ears, and when the head had turned through $23^{\circ}$ the image of the source would have turned through $17^{\circ}$-this $17^{\circ}$ must be compensated for by change of intensity at the two ears. As a matter of fact $I$ am inclined to think that in the case of the higher notes-perhaps in the case of all notes-the zone or are in which the soundimage appears is settled by the relative intensity at the two ears; the actual position of the images within this zone being produced by the maxima and minima within it produced by phasedifference at the ears.

In order to explain the existence of a movable image of the sound within this zone, we may suppose that the transmission of the sound impulse through some specialized part of the auditory apparatus or brain takes a definite time from each ear, and that the point where the impulses meet is the focus that gives rise to the sensation of a sound-image.

To explain the existence of two images, and perhaps three, we may suppose $\alpha$ and $\beta$ to be the crests of two successive waves; then, if the observer is facing the source, the crests of $\alpha$ arriving at the ear simultaneously produce an image at the centre of the sound-zone; $\alpha$ at the right ear and $\beta$ at the left give an image to the right of the centre, and $\alpha$ at the left ear and $\beta$ at the right give an image to the left of the centre.

If two equal tubes be applied to the ears, one with aperture 2 inches in diameter, and the other of ${ }_{10}^{6}$ of an inch, and both apertures be turned square on to the source, I find a deflexion of $20^{\circ}$ to be produced in the sound-zone, and within this the image moves about as before.

In order to determine whether intensity affected the position of the image when notes of medium pitch were concerned, one ear-tube was closed by a disk of aluminium luted on with clay. A hole was made through the centre of this disk, through which hole a cylinder of paper, 2 inches

* Further experiments with wave-lengths down to 2 inches would, however, seem to indicate that this law does not hold even roughly for short wave-lengths, the displacement being much larger than this law would give. 
long and $\frac{1}{2}$ inch in diameter, was inserted; the area of this tube was about $\frac{1}{25}$ of the area of the ear-tube and it projected $\frac{1}{4}$ inch beyond the disk. The outer $2 \frac{1}{2}$ inches of the tube was very loosely plugged with cotton-wool to suppress resonance.

A series of experiments was made. In one set the ear tube without the perforated disk was used, in the other the tube was used with the disk attached.

The tube was placed over the one ear, the other ear being free; the head faced the source of sound, and the apparent angular displacement of the image was noted.

The results are given in the following Table:-

Note of Wave-length $27 \cdot 6$ inches.

\begin{tabular}{|c|c|c|c|c|}
\hline \multirow{2}{*}{$\begin{array}{l}\text { Length of tube } \\
\text { applied to } \\
\text { the ear. }\end{array}$} & \multicolumn{2}{|c|}{ Tube applied to the Right ear. } & \multicolumn{2}{|c|}{ T'ube applied to the Left ear. } \\
\hline & $\begin{array}{l}\text { Angular dis- } \\
\text { placement } \\
\text { without per- } \\
\text { forated disk. }\end{array}$ & $\begin{array}{c}\text { Angular dis- } \\
\text { placement } \\
\text { with per- } \\
\text { forated disk. }\end{array}$ & $\begin{array}{c}\text { Angular dis- } \\
\text { placement } \\
\text { without per- } \\
\text { forated disk. }\end{array}$ & $\begin{array}{l}\text { Angular dis- } \\
\text { placement } \\
\text { with per- } \\
\text { forated disk. }\end{array}$ \\
\hline 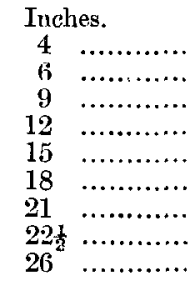 & $\begin{array}{ll}12 \circ & \\
24^{\circ} \mathrm{l} . & \\
45^{\circ} \mathrm{l} . & \\
60^{\circ} \mathrm{l} . \mathrm{l} & 50^{\circ} \mathrm{r} . \\
& 32^{\circ} \mathrm{r} . \\
& 28^{\circ} \mathrm{r} . \\
& 10^{\circ} \mathrm{r} \\
& 0^{\circ} \\
16^{\circ} 1 . & \end{array}$ & $\begin{array}{ll}30^{\circ} \mathrm{l} . & \\
36^{\circ} \mathrm{l} . & \\
60^{\circ} \mathrm{l} \& & 45^{\circ} \mathrm{r} . \\
& 24^{\circ} \mathrm{r} . \\
& 20^{\circ} \mathrm{r} \\
& 14^{\circ} \mathrm{r} \\
& 0^{\circ} \\
10^{\circ} \mathrm{l} . & \\
40^{\circ} \mathrm{l} . & \end{array}$ & 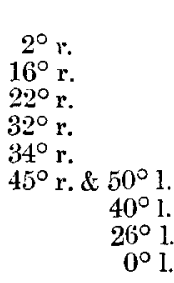 & 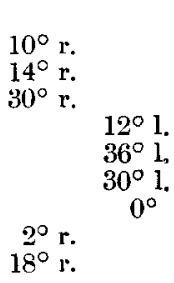 \\
\hline
\end{tabular}

From this it is evident that intensity plays an important part in fixing the position of the sound-image when there is a great difference of intensity at the two ears.

Another experiment which shows the part played by intensity, and yet how largely the apparent position is affected by phase at the same time, was tried. In this case the observer's left ear was towards the source of sound, the vertical plane throngh the ears passing through the source. Ear-tuhes of various lengths were applied to the right ear, and the head was kept fixed, the angle of displacement being noted.

The results are as follow :--

The source is considered zero-the point in front of the 
observer is $+90^{\circ}$, the point directly behind is $-90^{\circ}$ (where not marked negative the angle is to be taken as positive).

\begin{tabular}{|c|c|c|c|c|c|}
\hline \multicolumn{2}{|c|}{ Note of ware-length $13.8 \mathrm{in}$. } & \multicolumn{2}{|c|}{ Note of wave-length $19 \cdot 2$ in. } & \multicolumn{2}{|c|}{ Note of wave-length 40 in. } \\
\hline $\begin{array}{l}\text { Length of } \\
\text { ear-tube. }\end{array}$ & $\begin{array}{l}\text { Angular dis- } \\
\text { placement. }\end{array}$ & $\begin{array}{l}\text { Length of } \\
\text { ear-tube. }\end{array}$ & $\begin{array}{l}\text { Angular dis- } \\
\text { placement. }\end{array}$ & $\begin{array}{l}\text { Length of } \\
\text { ear-tube. }\end{array}$ & $\begin{array}{l}\text { Angular dis- } \\
\text { placement. }\end{array}$ \\
\hline 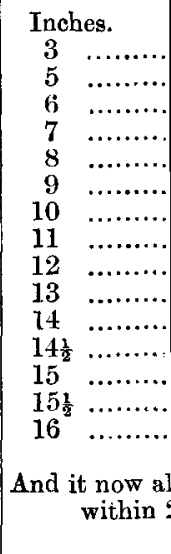 & \begin{tabular}{|c|c|c|c}
$-60^{\circ}$ \\
+60 \\
55 \\
45 \\
36 \\
0 \\
30 \\
80 \\
70 \\
60 \\
36 \\
0 \\
10 \\
15 \\
10 \\
\\
$20^{\circ}$ of 0.
\end{tabular} & 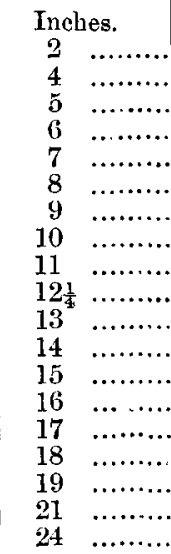 & $\begin{array}{c}0^{\circ} \\
45 \\
80 \\
75 \\
60 \\
50 \\
45 \\
36 \\
16 \\
0 \\
20 \\
40 \\
60 \\
60 \\
45 \\
38 \\
20 \\
0 \\
50\end{array}$ & 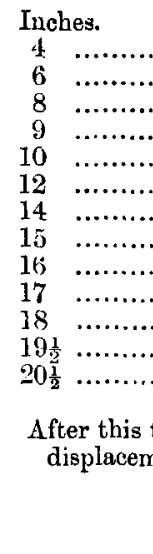 & $\begin{array}{c}0^{\circ} \\
8 \\
8 \\
90 \\
90 \\
80 \\
70 \\
60 \\
60 \\
50 \\
30 \\
12 \\
0 \\
\\
\text { he angle of } \\
\text { ent is small. }\end{array}$ \\
\hline
\end{tabular}

I simply record these results without attempting any explanation, beyond suggesting that sound-conduction through the bone and some portion of the brain-substance may perhaps play a part in fixing the sound-zone when the image is perceived.

It is to be remarked that as no special care was taken to suppress resonance in the above experiments, it is probable that some of the results are affected by it.

In order to determine the amount of displacement produced by a difference of phase in the arrival of sound at the ears, a pair of tubes 6 inches long and $2 \frac{2}{10}$ inches in diameter were taken. A pair of flat rectangular plates $4 \frac{1}{2}$ inches by $2 \frac{1}{2}$ inches were also taken, and in each of them a slit $1 \frac{1}{2}$ inches long and $\frac{6}{10}$ inch wide was cut across symmetrically near the centre. These plates were luted on to the outer ends of the ear-tubes with modelling-clay, and were so arranged that the central line of the slit was $\frac{6}{10} 0$ of an inch distant from the axis of the tube.

The observer faced the source of sound and applied these tubes to the ears, the slit of one tube being vertical and 
nearer the source, the other vertical and further from the source.

The position of the image was noted, and the tubes were then rotated through $180^{\circ}$ about their axis, and the position of the image again noted.

This arrangement made the conditions at both ears precisely the same as regards resonance and intensity for both observations, the only difference being that there was a difference of $2 \cdot 4$ inches in the length of the path of sound to the two ears in the two cases.

With this apparatus the results with two observers, myself and Mr. O. B. Clarke, were as follows:-

\begin{tabular}{|c|c|c|}
\hline \multirow{2}{*}{$\begin{array}{l}\text { Wave-length } \\
\text { of sound. }\end{array}$} & \multicolumn{2}{|c|}{ Angular displacement of image. } \\
\hline & Observer O. B. C. & Observer T. J. B. \\
\hline 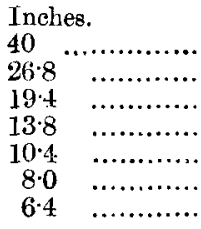 & $\begin{array}{l}18^{\circ} \\
18 \\
20 \\
18 \\
24 \\
18 \\
18\end{array}$ & $\begin{array}{l}12^{\circ} \\
14 \\
14 \\
14 \\
16 \\
14 \\
12\end{array}$ \\
\hline
\end{tabular}

It is remarkable that the angle of displacement should remain nearly the same with such a wide variation in wavelength.

Now if we take the diameter of the head through the ears to be $5 \frac{1}{2}$ inches, a movement of the head of $25^{\circ}$ would make a difference of $2 \frac{4}{10}$ inches in the distances of the ears from the source of sound.

Assuming that when the head is turned through $25^{\circ}$ the direction of the source is indicated exactly by the sensation of the image, this experiment shows that in the case of one observer an average of $6^{\circ}$, and in the case of the other observer of $11^{\circ}$, had to be made up by the displacement of the sound-image due to intensity or other cause. As regards myself, $I$ find that when my right ear is turned partly towards the source of sound and with eyes shut I point to it, I underestimate the angle from the symmetrical head-plane for sounds of 24 inches wave-length and over, and overestimate the angle when the left ear is turned towards the source.

With regard to the general intensity of the sound, I find that when the sound is fairly loud the apparent 
direction, when using ear-tubes and facing the source, remains almost the same when the sound becomes louder, the angle of displacenent becoming, if anything, somewhat smaller. In the case of the notes of greater frequency, however, the sound when dying away will, in my case, move through a considerable angle to the left, if its original position is near the source to start with-this is probably due to my left ear being more sensitive for feeble shrill sounds than the right ear.

In connexion with these methods of examining soundimages, an interesting experiment is to take two tubes of 2 inches or more in diameter, one say 12 inches long and the other 4 inches, and listen to a band of three or four instruments played in the open-the notes will be found to be scattered over a wide range, most being to the side of the short tube, some being in front and some being to the side of the long tube.

In listening with such a pair of tubes to two dogs furiously barking, the effect is at first quite alarming-one seems to be in the middle of a pack of dogs some of which are rushing viciously at one's throat, Preferably the tubes should be of metal sheet, and it is best, though not necessary, to surround them with a sheet of some rubber cloth or composition.

It remains to say something about the interference of trains of waves after reflexion in producing a change in the position of the image.

In one experiment, an organ-pipe was placed 5 feet from a flat wall and the observer stationed on a line, making an angle of $30^{\circ}$ with the wall, through the foot of the perpendicular from the organ-pipe on the wall. There was more difficulty in settling the direction than when there was no wall, and the apparent position seemed to be at the foot of the perpendicular on the wall: with other positions of the observer, the apparent image of the source varied between the source and this point.

When the positions of the observer and the source were interchanged, I obtained these results when working with a note of wave-length $26 \cdot 8$ inches.

Source of sound 40 feet distant.

Ear 30 inches from the wall-the only image lay on a line from the ear parallel to the wall.

(The image of the first harmonic of the stopped pipe was displaced $10^{\circ}$.)

As the head was moved nearer to the wall, the image 
moved gradually nearer to the source and arrived at the source when the ear was 16 inches from the wall.

A similar experiment with a note of wave-length $19 \cdot 4$ inches gave the image:-

on line parallel to the wall, with ear distant $17,39,61$ inches at the source, $40^{\circ}$ from the wall, with ear distant $24,48,58$ inches with ear distant 32,52 inches.

From these experiments it is clear that in noting the direction of a fog-horn at sea the observer should be well away from any reflecting surfaces of any kind. (In one experiment an umbrella held to one side of the head at a distance of 2 feet displaced the sound-image $20^{\circ}$.) I find that it adds to correctness in fixing the direction to have a flat board slung on the shoulders vertical and parallel to the axis of the ears. This increases the intensity in front and shuts off sound from the rear. I think it would also be better to have two short blasts of 3 seconds each, every half minute, at sea, rather than a long blast every minute.

Also fog-horns should be placed well above any reflecting surfaces, but it might add to their carrying power if a large disk or sounding-board was placed horizontally directly over them,

XXXII. On certain Bessel Integrals and the Coefficients of Mutual Induction of Coaxial Coils. By T. H. HAveLock, M.A., D.Sc.; Fellow of St. John's College, Cambridge; Lecturer in Applied Mathematics, Armstrong College, Newcastle-on-Tyne*

THE calculation of coefficients of mutual induction has been discussed by several writers from the time of Maxwell to the present, more accurate expressions being required as experimental methods have become more refined. The expressions are generally in one of two forms : they are either given in elliptic integrals, in which case numerical calculations are tedious, or given by a certain number of terms of a series.

The present paper brings forward another method of expressing the coefficients, namely in terms of integrals involving Bessel functions; series are obtained from these integrals, their general terms found, and their convergence tested. In certain cases series are obtained which seem to be simpler and better adapted for numerical calculation than

* Communicated by the Author. 